\title{
O ESTUDANTE MANUEL ANTÔNIO ÁLVARES DE AZEVEDO (1).
}

Quando o Prof. Orestes Rosolia, muito digno Diretor do nosso Curso Ginasial, me deu a grata incumbência, que agradeço muito, de falar-vos sôbre um dos mais complexos e completos escritores paulistas, Manuel Antônio Alvares de Azevedo, pensei logo em tratá-lo como estudante.

E que o estudo total de um tão difícil poeta, pediria o exame demorado da sua vida, da critica dos outros autores, da obra que o poeta deixou. E nada disto iremos abordar.

Em matéria de critica, digamos apenas que é uma das figuras: mais impressionantes da nossa cultura.

Em se tratando da obra, basta dizermos que, apesar de estudante exemplar, de prof undo estudioso, foi poeta, dramaturgo, contista, romancista, crítico literário, historiador da literatura, conferencista, orador, epistológrafo. Em quatro anos de produçāo literária, deixou-nos, na ediçāo em dois tomos de Homero Pires, os seguintes trabalhos: - "Lira dos vinte anos", "Poesias diversas", "Poema do frade", "O Conde Lopo", "Macário", "Noite na taverna", "O livro de Fra. Gondicário", "Estudos literários", "Discursos" e "Cartas".

A vida de Álvares de Azevedo - se agora tôssemos traçá-la - pediria três capitulos: - A genialidade do intelectual, A férrea vontade do estudioso, A debilidade física do homem, três fôrças gerais, desdobrando-se em outras inúmeras fôrças particulares, que se inter-agem, dando em resultado êsse fenômeno paulista, próximo parente de Edgar Allan Poe, o gênio meio solitário na América.

Manuel Antônio Álvares de Azevedo é a assombrosa conjunçāo de duas fôrças excepcionais: - a notabilíssima ascendência em duas familias que se distinguiram no cenário cultural do Brasil; a fibra desbravadora do pioneiro, na escola, na cultura, na literatura. Primeiro em tudo, foi o estudante incansável, o estudioso. incansável, o escritor incansável.

(1). - Palestra pronunciada no auditório do Instituto de Educação Caetano de Campos, na tarde de 25 de abril de 1952 , primeiro centenário da. morte do poeta. 
Fôrças que enfraqueceriam, cada uma de per si, muita gente forte e que, no caso de Álvares de Azevedo, encontraram o apôio de um débil organismo, o que vale dizer: - nāo encontraram apôio algum. Daí, a falta de saúde culminar em morte prematura, fatal desenlace, acelerado, quase que em inconsciência, pelas mesmas duas fôrças positivas portentosas. A vida de Manuel Antônio é a história da debilidade, esmagada ao pêso do gênio e ao pêso da vontade: - a haste da balança não pôde resistir ao pêso dos dois pratos.

Hoje, porém, nāo veremos o estudioso insaciável, o escritor insaciável. Basta dizermos que conhecia tudo de essencial da literatura greco-latina e das literaturas modernas; e tudo em maior parte conhecido nas fontes originais. Basta, para só lembrarmos a obra, a relaçāo que arrolamos.

E embora nāo tratemos, hoje, do ledor e escritor, nāo nos esqueçamos, porém, de frisar bem que, homem de espantosa fôrça de vontade (refletida e espontânea), em apenas quatro anos de produçāo, interrompida pelo estudo profundo e pelas leituras infindáveis, Álvares de Azevedo nos legou cêrca de mil páginas, ond os lampejos do gênio, de espaço a espaço, fulguram, como luzes, à beira de uma estrada percorrida em velocíssimo veículo, projetado para aquela meta que só o seu condutor antevia tão próxima: a morte prematura.

Contentemo-nos, hoje, apenas com uma sintese da formação cultural de Allvares de Azevedo, feita com dados bebidos em Domingos Jaci Monteiro, Joaquim Norberto, Artur Mota, Afonso Schmidt, Homero Pires e Edgard Cavalheiro (2).

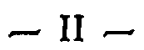

Álvares de Azevedo, filho legitimo do Dr. Inácio Manuel Ȧlvares de Azevedo e D." Maria Luísa Silveira da Mota Azevedo, nasceu na casa do seu avô materno, Silveira da Mota, situada à Rua Quintino Bocaiuva, esquina da Rua Senador Feijó, na cidade de São Paulo, às duas horas da tarde de 12 de setembro de 1831 , e morreu às cinco horas da tarde de um domingo da Ressurreiçāo, dia 25 de abril de 1852 - exatamente há cem anos passados na casa da Rua do Infante, n..$^{\circ} 1$, hoje Dois de Dezembro, n..$^{\circ} 13$, da cidade do Rio de Janeiro e onde, em 1939, se situava o Hotel Seleto. Morreu, portanto, adolescente, com apenas vinte anos, sete meses e treze dias.

Em 1833, aos dois anos, foi para o Rio, onde, em 1835, aos quatro, caiu gravemente doente, com forte febre, resultante do aba-

(2). - Ver a Bibliografia, na parte final. 
lo nervoso que sofreu, pela morte, em Niterói, de seu irmāozinho Inácio Manuel, de dois anos.

Assim, por motivo da fraqueza que lhe ficou desta enfermidade, de 1835 a 1839 , dos quatro aos oito anos - embora já aos seis o iniciassem nas primeiras letras - seus pais não lhe cuidaram sèriamente da educaçāo.

Os estudos de Álvares de Azevedo começam, pois, verdadeiramente, no Colégio Stoll, onde, de 1840 a 1844, fêz o curso primário e boa parte do secundário.

Entre o Colégio Stoll e o "Pedro II", esteve estudando em Sāo Paulo (de agôsto a dezembro de 1844); no Rio (de janeiro a junho de 1845) fêz os preparatórios para o "Pedro II".

Durante dois anos e meio (de junho de 45 a dezembro de 47 ) cursou êste Colégio.

Na Faculdade de Direito, estudou, de 1848 a 1851, nāo chegando, pela morte em 52, a concluir o curso de cinco anos. Mais um ano, e teria, aos vinte e um, acabado a sua formaçāo total, idade verdadeiramente notável para a conclusão do Curso Superior.

O rapazinho genial, de vontade de aço, mas frágil de corpo, faria, em doze anos, de 1840 a 1852, o seu Curso Primário, Secundário e Superior. E que cursos! Cursos em que, normalmente, gastamos hoje dezesseis anos. E êle os fêz, lendo alvoroçadamente, alvoroçadamente escrevendo. Foi, ou nāo foi uma vontade dócil aos caprichos do gênio?!

\section{- III -}

Mas vejamos o menino mais de perto: -

Alvares de Azevedo, durante mais de quatro anos (de janeiro de 1840 a 1844) esteve estudando no Colégio Stoll.

Foi, ali, a menina dos olhos do seu Diretor, Educador extraordinário, digno de todos os louvores.

Nem bem três meses se passaram e, já por volta de março de 1840 , o Dr. Stoll, em francês que traduzimos, escrevia, esperançoso, ao pai do poeta: - "Vosso Manuelzinho me encanta sempre, cada vez mais; é, sem dúvida, a mais bela esperança de meu colégio, excepto para a ginástica, em que é o último..."

Em outubro de 1840, continuava informando, já entusiasmado e crítico: - "Vosso filho é sempre o melhor de meus alunos, pelo espirito, pela inteligência, pelo amável bom-humor, e sobretudo pelo coraçāo... Quanto mais analiso esta criança, tanto mais me surge ensejo de felicitar-vos por terdes um filho assim. Que Deus lhe dê vida e saúde e vereis que êle se tornará qualquer cousa de bom e de muito bom."

Em novembro de 1840, já se torna profético: - "Em verdade, êle nāo tem perdido tempo êste ano, e, se continuar assim, isto 
dará um brasileiro que poderá medir-se com as primeiras capacidades européias."

Mas, em abril de 1841, é mais comovido, mais intimo, mais profundo: - "Nosso heróizinho é, sempre, minha glória e minha felicidade: - reúne - o que é muito raro - a maior inocência de costumes à mais vasta capacidade intelectual que encontrei, na. América, num menino de sua idade... Nada me encanta mais que vê-lo - após ter superado a todos os grandes, nas lições ocupar-se, nos brinquedos, em plantar flôres sem raiz, para fazer um jardinzinho de uma hora de duraçāo, ou ainda em levantar uma casinha que o vento põe por terra."

Finalmente, em maio de 1841 , a consagraçāo já é definitiva: - "Recebi a visita do Snr. Guimarāes (o Dr. Francisco José Pinheiro Guimarāes) que - assombrado com os progressos de vosso Manuelzinho - quer confiar-me seus dois filhos. Na verdade, - Maneco é o meu recrutador. Mais de quarenta pessoas vêm felicitar-me por ter feito maravilhas com êle. Eu ouvi um de vossos; alunos - dizem. Mas é verdadeiramente admirável como êle fala: Francês, Inglês, declama, sabe a História e a Geografia!" (3).

Gostariamos de comentar, palavra por palavra, as expressöes do Dr. Stoll. Porém, nāo há tempo e é bom: - nāo cometeremos. a heresia. Basta lembrarmos que estas palavras se referiam a um. menino de nove anos e que a profecia do Dr. Stoll se cumpriu totalmente.

Por êsse tempo, o nosso poeta já fazia suas leituras: - "Os Lusiadas" de Camões, a "Henriqueida" de Voltaire. Gostava muito do desenho. Uma vez, aos dez anos, para celebrar o aniversário do pai, fêz, alusivos à data, os seus primeiros versos; eram em francês e acompanhavam um desenho que rabiscara.

$\mathrm{E}$ o entremez do Colégio?! Ah! como êste define a humanidade profunda, a perspicácia do grande Diretor; como define a vocaçāo artística do menininho: - vocaçāo já para, nāo só, imitando, criar, como para representar cenas humoristicas!

Foi assim que se deu: - Manuel Antonio tinha dez anos: Era no Colégio do Dr. Stoll. Ulma ocasiāo, êste admoestara enèr-: gicamente, por um fato qualquer, a três empregados do Colégio;. todos de nações diferentes. Pois nāo há-de ver que, um dia, surgiu, ao Dr. Stoll, um dos criados, a se queixar de que o diabinho do Manuel Antônio o ridicularizava, conjuntamente com outros colegas! O Dr. Stoll, severo Diretor, nāo tolerava o desrespeito: propõe-se repreendê-lo. A cena se desenrolava numa sala de estudo. Os alunos estavam em descanso. O Dr. vai; mas, rente com a porta, pára, hesitando. Para nāo agir só por informaçāo alheia, para nāo castigar precipitadamente, perscruta e escuta pela

(3). - Ver estas opiniōes do Dr. Stoll, em Domingos Jaci Monteiro, obra citada na Bibliografia, pgs. 195' e 196. 
Fechadura: - tanto the merecia cuidado o seu pequeno gênio, como lhe chamava em suas cartas! Entăo, abrindo abruptamente a porta, caminhou para Manuel Antônio e... lhe deu um apertado abraço! Stoll, tāo bem vira, imitados por êle, o seu modo de ser. a sua gesticulação, a sua fala de sotaque estrangeirado, que nāo pôde deixar de - por êste abraço, carregado de calorosa isençāo - coroar de bom êxito a primeira peça que o comediógrafo menino bosquejara, e para cuja concretizaçāo convidara os colegas!

Alvares de Azevedo era assim! Assim era o extraordinário Dr. Stoll!

\section{- IV -}

Mas, precisando o Dr. Stoll deixar a direção do estabelecimento, e nāo sendo muito bom o estado de saúde do nosso poeta, veio êste, pela primeira vez e a conselho médico, para São Paulo, no correr de agôsto de 1844, em companhia de seu tio, o Dr. José Inácio Silveira da Mota.

Despedindo-se, no album de sua dileta irmā Maria Luisa, deixou quatro versos em francês, talvez imitaçāo de Mlle. Flaugergues.

Aqui, melhorou. Continuou os estudos, fêz exames de Francês, Inglês e Latim. Deixou de prestar os de História e Geografia: - era muito novo para começar a estudar o Direito.

$E_{m}$ fins de 1844, voltou para o Rio. Até junho de 1845, preparou-se com o Barāo de Planitz e, no "Pedro II", prestou os exames exigidos.

Em 1845, fêz o quinto ano do internato do Colégio, em que se matriculara, a 2 de junho, como aluno galgo. Era o n. 430 . Dos seus colegas, nāo se sabem os nomes. E - tirante um tal Antônio Maximiano de Araújo Pereira, nos exames do fim do ano - a sua turma passou tôda com grau pleno.

Em 1846, . cursou o sexto ano. No fim, conquistou, conjuntamente com outros colegas, o mesmo grau. Grau pleno e a primeira mençāo honrosa.

Em 1847, cursou o sétimo e último ano. De novo conquistou aprovaçà́o plena e a primeira menção honrosa.

Assim, aos 16 anos, em sessão celebrada a 5 de dezembro de 1847, recebeu, solene e merecidamente, o diploma de Bacharel em Letras.

- No quinto ano do Colégio Pedro II, teve, como Professor de Grego, a Joaquim Caetano Pereira da Silva; como Professor de Alemāo, ao Barāo de Planitz, de quem guardou sempre saudosa memória. 
No sexto ano, foi seu Professor de Filosofia, Domingos José Gonçalves de Magalhāes, depois Visconde de Araguaia, que, em 1836, iniciara o romantismo brasileiro, com os "Suspiros poéticos e Saudades"; Santiago Nunes Ribeiro, de origem chilena, foi seu Professor de História Moderna, Retórica e Poética.

No sétimo ano, lecionando-o, encontramos Calógeras e Tautphoeus. $\mathrm{O}$ primeiro, historiador e de origem grega. $\mathrm{O}$ segundo, notável naturalista alemão.

Como se vê, o Corpo Docente do "Pedro II", na época, estava à altura das necessidades do aluno Manuel Antônio.

Mas, apesar de tudo, o rapazinho - acostumado àquele regime de eleiçāo criado pelo grande Stoll - estranhou muito o Colégio, nos primeiros tempos. Era altivo e dificilmente se adaptava a certos usos. Gostava do desenho, amava a travessura, e, sem querer, lá ia o Manuel Antônio caricaturando empregados do Colégio. Por isto, e nāo por mais, embora fôsse, como vimos, um cabeça de turma, várias vêzes visitou o quarto éscuro do "Pedro. II". Afinal, percebendo que os castigos nāo lhe quebravam o gênio, e que, pelo contrário, êste já augurava excepcional futuro, a Direçāo da Casa - levañdo também em conta que a sua precária saúde mais se ressentia com as punições - resolveu, de um certo ponto em diante, deixá-lo em paz. Aliás, seus colegas não só o estimavam, como lhe admiravam, principalmente, a imaginaçāo, e os sérios conhecimentos de História e Filosofia.

E, já nesse tempo, ia traduzindo e lendo os bons autores das várias literaturas. Nāo só. Ia também compondo. "A mor parte. porém, dos seus primeiros escritos e papéis - diz Domingos Jaci Monteiro - perdeu-se entre as rosas desfolhadas de sua infância... Tudo isso era ainda nada: apenas singelos arrojos de criança que denunciavam precocemente os feitos do futuro homem, como essas faíscas envoltas em fumo e cinzas que o vulcāo atira às auras da planicie, antes de arremessar aos furacões das alturas as flamas que tornam noites em dias..." (4).

Agora, Sāo Paulo, agora a Academia.

Quando Álvares de Azevedo estudou na Academia de Direito, São Paulo já era ambiente bastante culto. Possuia livrarias e teatro; contava, em 1850, quarenta e sete jornais, número que aumentou, depois de 1851. Por esta imprensa, debatiam-se problemas da época e digladiavam-se acirradas correntes politicas. Fora da Academia, eram nomes notáveis os de Gabriel Rodrigues dos Santos, Martim Francisco, Pimenta Bueno, Antônio Joaquim Ri-

(4). - Domingos Jaci Monteiro, obra citada na Bibliografia, pgs. 199 e 200. 
bas. Francisco Otaviano de Almeida Rosa, formado em 1845, ainda aqui morava: - era o poeta predileto da mocidade acadêmica, que lhe copiava os versos, nas paredes das repúblicas, onde, também encantados, vinham decorá-los os calouros.

O meio acadêmico também lhe foi bastante propicio: - contava com imprensa, associações, distintos professôres, contemporâneos ilustres, amizades.

A imprensa acadêmica do tempo representava-se pela "A Violeta", "O fris", "O Acaiaba", os "Ensaios Literários", os "Ensaios Literários do Ateneu Paulistano" e a "Revista Mensal do Ensaio Filosófico Paulistano".

Como associações estudantinas sobressaiam-se duas: - o Ateneu Paulistano, cujo porta-voz eram os seus "Ensaios Literários", e o Ensaio Filosófico Paulistano, que tinha como órgāo a "Revista Mensal", fundada por Álvares de Azevedo.

Entre os Professôres que, de 1848 a 1851, teriam lecionado ao nosso poeta, citamos os seguintes: - Avelar Brotero, lente de Direito Natural; Veiga Cabral, de Direito Civil; Silveira da Mota, tio de Alvares de Azevedo, lente de Prática do Processo. Mais novos, ai lecionavam ainda, Joāo Crispiniano e Ramalho, mais tarde notáveis jurisconsultos.

Entre os contemporâneos de Alvares de Azevedo, destacam-se: - No primeiro ano, Batista Caetano de Almeida Nogueira. No segundo: - Bernardo Guimarāes e Aureliano Lessa. No terceiro: - José de Alencar. No quarto ano. Silveira e Sousa. No quinto: - Perdigāo Malheiro, Joāo Cardoso de Meneses, futuro Barāo de Paranàpiacaba, e Paulo do Vale. Chegariam depois: em 1849, José Bonifácio, o Moço; em 1850, Félix Xavier da Cunha; em 1851. Américo Brasiliense, Ferreira Viana, Paulino José Soares de Sousa. Outros, como Duarte de Azevedo, Andrade Figueira, Flávio Farnese, que chegaram em 1852, nāo tiveram, talvez, ocasiāo de conhecê-lo pessoalmente.

Entre as amizades do poeta, avulta, principalmente, o nome de Luis Antônio da Silva Nunes, amigo profundamente estimado, que lhe foi, nāo só o confidente dileto, como também, mais tarde, o editor do "O Conde Lopo". Mas havia, também, os nomes de Aureliano José Lessa e Bernardo da Silva Guimarāes, com os quais, èm 1851, iria, de colaboraçāo, editar um livro de versos, "As três liras", cada poeta com sua parte.

E desta amizade se valeram Bernardo e Aureliano de uma feita em que se acharam sem dinheiro, fato comunissimo entre estudantes. E como o arranjaram? Pediram ao coléga Manuel Antônio, extremamente pálido, que se fingisse de morto. Pediram-lhe, êle acedeu, e lá ficou morto, estirado na cama. Angariados os dorativos para o enterramento, e transmudados êstes numa suculenta ceia, lá para os fundos da república, nasceu também, no finado, uma forte vontade de ir compartilhar dela! E, para isto, levan- 
tou-se: - ressuscitou, livido, dentre a brancura dos lençoiis... E os guardadores do velório? Pernas, para que vos quero! Foi um esparramo dos seiscentos diabos!

Agora, de um fato relativamente inocente como êste, concluir que Alvares de Azevedo era um dos cabeças da Epicuréia, achamos muito forte. O poeta nāo tinha espirito, nem corpo, nem tempo para isto. Suas orgias foram, pura, essencialmente cerebrais.

Mas, falamos em Epicuréia, sem dizer o que fôsse. Era uma sociedade que já vinha de 1845 . Seus sócios eram, geralmente, acadêmicos. Manfredo, Lara, Giaour, Marino Faliero, Beppo, Conrado, Sardanapalo, Mazeppa, Caim eram os nomes que adotavam, todos tirados das personagens de Byron. Suas reuniōes eram nos arrabaldes, sem lugar fixo. Como a sua finalidade era realizar, imitando, as extravagâncias da vida e da obra do Lorde inglês, a Epicuréia cometeu os atos mais deploráveis, de que Álvares de Azevedo poderia ter sido - quando muito - um atento. curioso observador, a recolher elementos para a "Noite na taverna".

Quem - espirito elevado, em tāo pouco tempo, com tāo pouca saúde - tanto estudou, leu e escreveu, não poderia ter bebido muito na Epicuréia, fonte envenenada de desgaste físico, moral e intelectual.

A verdade é que: - "Sentado nos bancos da faculdade juridica, (diz Joaquim Norberto) Álvares de Azevedo nem mediu fôrças, nem calculou tempo; sacrificou tudo ao estudo levado além das raias do possivel. "Há uma coisa, dizia êle escudado com a autoridade de Agostinho Thierry, que vale mais do que os gozos materiais, mais que a fortuna, mais que a saúde mesma - o sacrifício à ciência!" Estudou profundamente o direito romano, como a origem de todos os direitos, e o código do comércio, ainda há pouco sancionado, já êle o sabia de cor e para logo analisou-o, confrontando-o com os códigos estrangeiros. Juízes competentes admiravam seus notáveis conhecimentos em diversos ramos das ciências sociais. Advogados distintos e até seu próprio pai o consultavam durante as férias, e entregavam-lhe causas importantes; e os seus trabalhos, que apenas necessitavam dos retoques da fraseologia da praxe, eram coroados pelas decisões dos tribunais" (5).

E note-se que - segundo Homero Pires - quando Alvares de Azevedo o estudava, o Direito Romano não era ainda Cadeira do Curso.

As suas leituras, êle as ia fazendo durante o periodo escolar. As férias, êle as aproveitava, principalmente, para compor. nebres.

Durante o curso, fêz duas conferências e duas orações fú-

(5). - Joaquim Norberto, obra citada na Bibliografia, pgs. 35 e 36. 
A primeira conferência, em que tratou da missāo literária das Academias, pronuncioura a 11 de agôsto de 1849 , no segundo ano do Curso, numa sessāo em que se comemorava o aniversário da criação dos Cursos Jurídicos no Brasil. Conferência que saiu em opúsculo.

A segunda, em que abordou a missāo politica das Academias, recitou-a em 9 de maio de 1850 , no terceiro ano, quando se inaugurou a associação acadêmica Ensaio Filosófico Paulistano.

A respeito dêste trabalho, em que trata de Educaçāo e Politica, e que causou estranheza a seu pai, por uma certa liberdade de idéias, escreveu Manuel Antônio uma carta, visando a acalmar os escrúpulos paternos. Nela, diz o seguinte: - "Quanto ao que falei sôbre instruçāo pública, sôbre o desleixo dos governos de todos os credos no Brasil, bem se vê que nisso nāo há idéia nenhu- . ma de liberalismo exagerado, e muito menos de republicanismo. As minhas idéias sôbre política resumem-se em querer menos palávras e mais convicções, menos alarido de liberalismo e mais instituições asseladas dêle." (6).

A primeira oraçāo fúnebre, êle a proferiu, em nome dos colegas, a 12 de setembro de 1850 (exatamente dia do seu aniversário), no túmulo de um quinto-anista amigo, Feliciano Coelho Duarte, que se suicidara por amor.

A segunda oraçāo fúnebre, fê-la, ainda interpretando o sentimento dos colegas, por ocasiāo da morte de Joāo Batista da Silva Pereira, quinto-anista também, falecido a 15 de setembro de 1851 , exatamente três dias depois da data natalícia do poeta.

Destas mortes seguidas de quinto-anistas e destas homenagens póstumas, lhe nasceu a conviç̧ão de que o terceiro a morrer, em 1852, seria êle. Mau augúrio que, infelizmente, se realizou.

E foi por esta ocasiāo que veio a conhecê-lo o também desditoso Paulo Eiró: - "Eu vi-o uma só vez em minha vida; mas nunca me poderei esquecer dêsse instante. Era na velha igreja de S. Francisco, em São Paulo. Armavam o templo para celebrar as exéquias do estudante João Batista Pereira. Um soberbo catâfalco erguia-se até o mais alto da nave, tendo escritos nas suas quatro faces versos sentidos e lúgubres. Li-os, e confesso que me pareceram detestáveis. "Quem é o autor?" - perguntei a um primo que me acompanhara até a igreja e que já gozava das honras de calouro. "Aquêle moço que está ali, sentado em um banco". Era ĉle, Azevedo; o pálido sonhador. Seu olhar distraído e melancólico estava fito no monumento fúnebre, como se contemplasse alguma visão que lhe aparecera bem vêzes na bruma tristonha da noite. Parecia Hamlet considerando o espectro do seu pai" (7).

(6). - "Obras completas de Álvares de Azevedo", S." edição. Organizada e anotada por Homero Pires, Segundo tomo, "Cartas", pg. 520.

(7). - Afonso Schmidt: - obra citada na Bibliografia. 


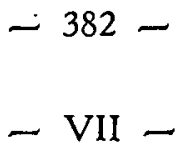

E agora, para rematar, vejamos alguma coisa mais intima: os lugares onde morou, o teor normal da sua vida, um esbôço do seu perfil, a linha evolutiva do seu espírito.

Em São Paulo, morou, primeiramente, na Chácara dos Inglêses, situada na Rua da Glória. À frente, um cemitério; ao lado, um casarāo arruinado. Aqui, Álvares de Azevedo nāo se sentia muito bem. E crê Edgard Cavalheiro que êste local tenha agravado o espirito já lúgubre do poeta: - contam as novelas inspiradas nestas ruinas, chamadas "as ruinas da Glória", que elas eram, à noite, verdadeiramente impressionantes. E para agravar o efeito, lá estava, próximo, o cemitério. Vai morar, após, num pequeno e infecto quarto da Rua Boa Vista; aqui vive muito pouco tempo. Passa, depois, a residir na Consolaçāo e, em seguida, na ladeira de São Francisco. Aqui é que - dizem - escrevia, na parede, o nome dos quinto-anistas que iam morrendo.

Normalmente, nos bons tempos, levantava-se cedo, por volta das seis. Ia tomar leite e, após, até às sete, dava um pequeno passeio. Achando que a melhor hora para o estudo era a manhā, gastava duas horas, das sete às nove, revendo a matéria do dia. Em seguida, ia para a Faculdade. Tinha vagas as horas da tarde. Recolhia-se cedo. E a chama do candieiro ficava fumegando até tarde: - Dante, a Bíblia, Shakespeare, Byron...

Alvares de Azevedo era homem de pequena estatura, delicada. compleição. De testa ampla, tez morena, muito pálido, palidez assinalada nāo só por Paulo Eiró, como também por Bernardo Guimarāes em "Rosaura, a enjeitada". A voz, fina e de pouco volume, emprestava-lhe à palavra uma certa suavidade, uma certa macieza.

Era um bom amigo; às vêzes, um pouco altivo. Uma alma caridosa e afável. Um admirável conversador. Üma vigorosa imaginação, atraída pelo fantástico, pelo terrivel, comprazendo-se no fünebre, no sinistro.

$\mathrm{Na}$ infância, fôra brincalhāo, alegre: - bom humor que transparece, claro, no entremez do Colégio Stoll, nas caricaturas do "Pedro II", no velório improvisado por Bernardo. Alegre e triso- 
nho continuou, até ainda além do primeiro ano da Faculdade. Depois, seu riso começou a perder a alegria; a melancolia veio chegando...

No comêço, deve ter-lhe feito bem a súbita liberdade, conquistada com o ingresso na Academia: - acabara-se aquela rigidez do Internato. Entāo, Álvares de Azevedo procurou ambientar-se, visitando amigos da familia, frequentando bailes. Mas, logo começou a sentir a falta da casa paterna, dos desvelos da mãe e da irmă. Foi-se entristecendo, ensimesmando, entediando, sem amores e quase sem amizades.

Já nas férias do segundo ano, foi, de Sāo Paulo para o Rio, bastante triste.

"Desde entāo - diz Domingos Jaci Monteiro - tudo quanto escreveu teve êsse caráter mais ou menos epigramático, mais ou menos extravagante de quem descrê do mundo e ri-se dêle, ou êsse cáráter, ora delirante, ora triste, de quem se entrega às ilusões para esquecer-se, de quem só espera - talvez - o futuro para sua memória, e vê no presente a imagem do acabamento..." (8).

Está-se quase no fim de uma cadeia dolorosa: - melancolia, concentraçāo, solidāo, tédio, pressentimento e angústia da morte.

Daquela morte que depressa veio, e nos deixou - a soar até hoje nos ouvidos; a confranger-nos o coraçāo e a umidecer-nos os olhos - aquêle balido de ovelha que morre assustada e inocente: - "Que fatalidade, meu Pai!"

E essa fatalidade nāo a sentiu só êle! Sentiram-na, também, José Bonifácio, ó Moço, Ferreira Viana, Duarte de Azevedo, Xavier da Cunha, Paulino Soares de Sousa, todos aquêles catorze acadêmicos que, sob a presidência do Diretor da Academia de Direito, Amaral Gurgel, recitaram poesias e proferiram discursos, naquela memorável sessāo que, a 23 de maio de 1852 , o Ensaio Filosófico Paulistano fêz realizar, em memória do seu fundador, o bacharel Manuel Antônio Allvares de Azevedo, sem nenhum favor, a maior capacidade cerebral que já passou sob as. Arcadas da Faculdade de Direito da Universidade de Sāo Paulo.

MANOEL CERQUEIRA LEITE Live-docente de Literatura Brasileira (U. S. P.).

(8). - Domingos Jaci Monteiro: - obra citada na Bibliografia, pg. 205. 


\section{B I B L IO GR A F I A}

1). - Domingos Jaci Monteiro: - "Discurso biográfico do Bacharel M. A. Alvares de Azevedo", recitado na quarta sessão solene do Ginásio Brasileiro, pelo sócio efetivo e primeiro secretário Domingos Jaci Monteiro, (12 de outubro de 1852), in "Obras de Manuel Antônio Alvares de Azevedo", precedidas do juizo crítico de escritores nacionais e estrangeiros e de uma noticia sôbre o autor e suas obras por J. Norberto de S. S., Sétima edição, Tomo primeiro, H. Garnier, Livreiro-editor, Rio de Janeiro, Paris, S/data, (1900), pgs. 191 a 218.

2). - Joaquim Norberto de Sousa Silva:- - Noticia sôbre o autor e suas obras", (lida em uma das 'sessões do Instituto Histórico Brasileiro, no ano de 1872), in "Obras de Manuel Antônio Alvares de Azevedo", já citadas, Tomo primeiro, pgs. 29 a 72 .

3). - Artur Mota: - "Alvares de Azevedo", in "Vultos e livros", (Academia Brasileira de Letras), Primeira série, Monteiro Lobato e Cia., São Paulo, 1921, pg. 28, Nota 1.

4). - Afonso Schmidt: - "A vida de Paulo Eiró", Seguida de uma coletânea inédita de suas poesias, organizada, prefaciada e anotada por José A. Gonsalves, Ilustrações de Wasth Rodrigues, Cia. Editôra Nacional, São Paulo, 1940, pgs. 122 e 123.

5). - Homero Pires: - "Allvares de Azevedo", in "Obras completas de Alvares de Azevedo", Oitava edição, Organizada e anotada por Homero Pires, Em dois tomos, Primeiro Tomo, Cia. Editôra Nacional, São Paulo, 1942, pgs. XI a XXVI.

6): - Edgard Cavalheiro: - "Alvares de Azevedo", (trecho de um estudo), in "Poesias completas de Alvares de Azevedo". Segundo tomo, Edição rigorosamente revista, Livraria-editôra Zélio Valverde, Rio de Janeiro. 1943, pgs. VII a XIV. 